ISSN 2236-0859

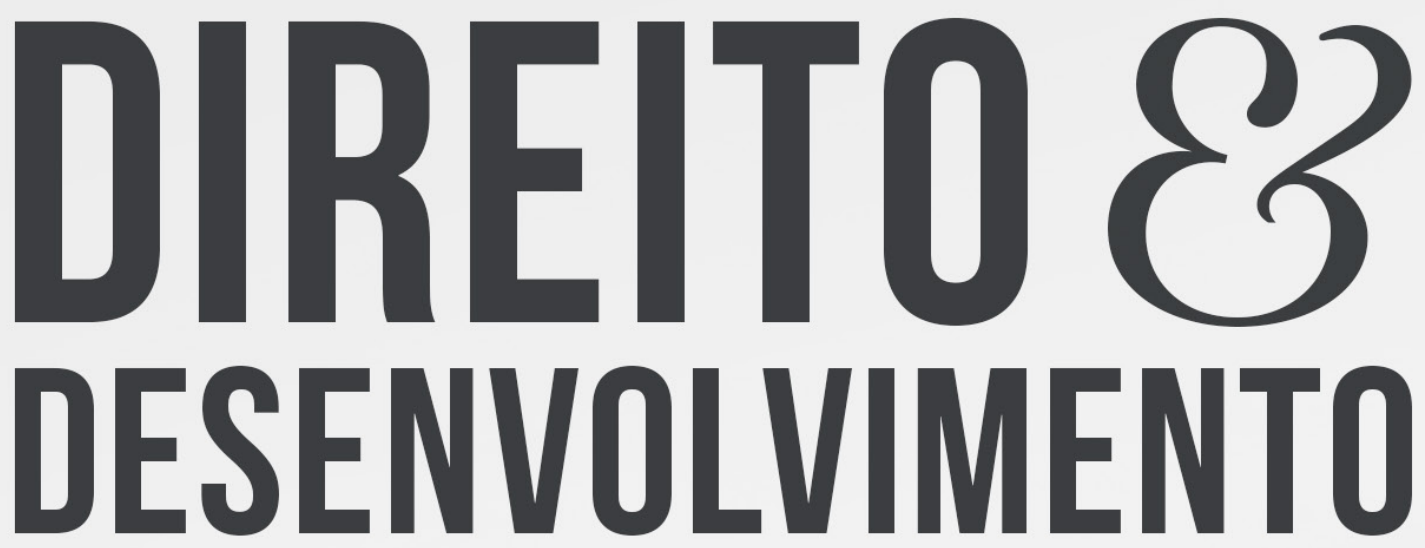

REVISTA DO PROGRAMA DE PÓS-GRADUAÇÃO EM DIREITO MESTRADO EM DIREITO E DESENVOLVIMENTO SUSTENTÁVEL

GOVERNANCSA GLOBAL EODESENVOLVIMENTONA SUA PLURIDIMENSIONALIDADE: UM OLHAR SOBRE A AGENDA 2030 DAS NAÇÕES UNIDAS

TUANA PAULA LAVALL

GIOVANNI OLSSON 


\title{
GOVERNANÇA GLOBAL E O DESENVOLVIMENTO NA SUA PLURIDIMENSIONALIDADE: UM OLHAR SOBRE A AGENDA 2030 DAS NAÇÕES UNIDAS
}

\author{
GLOBAL GOVERNANCE AND DEVELOPMENT IN THEIR \\ MULTIDIMENSIONALITY: A LOOK AT UNITED NATIONS 2030 \\ AGENDA
}

Recebido: 29/03/2019

Tuana Paula Lavall ${ }^{1}$

Aprovado: 17/06/2019

Giovanni Olsson ${ }^{2}$

\section{RESUMO:}

O artigo investiga como a Agenda 2030 das Nações Unidas afigura-se no marco da governança global para o desenvolvimento sustentável. Com o emprego do método dedutivo e por meio de pesquisa qualitativa, cuida, incialmente, da relação entre governança e desenvolvimento sustentável, enfatizando a incorporação da segunda temática no âmbito da ONU. Trata, também, das particularidades da Agenda 2030, explorando conceitos, inerentes ao tema governança, implicados no plano de ação pós-2015. Conclui que a Agenda 2030 constitui instrumento de governança por meio de metas que contempla fundamentos para um projeto de desenvolvimento articulador das dimensões ambiental, social, econômica e institucional, e passível de ser compartilhado em nível global.

Palavras-chave: Desenvolvimento sustentável. Governança global. Agenda 2030. Organização das Nações Unidas. Objetivos de Desenvolvimento Sustentável.

\begin{abstract}
:
The article looks at how the United Nations 2030 Agenda appears within the framework of global governance for sustainable development. With the use of the deductive method and through qualitative research, it first deals with the relationship between governance and sustainable development, emphasizing the incorporation of the second theme within the UN. It also deals with the particularities of 2030 Agenda, exploring concepts inherent in the governance theme that are implicated in the post 2015 action plan. It concludes that the Agenda 2030 is an instrument of governance through goals that contemplates the foundations for a development project articulating the environmental, social, economic and institutional dimensions.
\end{abstract}

Keywords: Sustainable development. Global governance. 2030 Agenda. Organization of the United Nations. Sustainable Development Objectives.

1 Mestranda em Direito pela Universidade Comunitária da Região de Chapecó (Unochapecó).

E-mail: tuanalavall@gmail.com

2 Doutor em Direito (UFSC). Mestre em Direito (UFSC), Professor Permanente do Programa de Pós-Graduação em Direito da

Universidade Comunitária Regional na linha Atores Internacionais (UNO-SC). E-mail: golsson71@gmail.com 


\section{INTRODUÇÃO}

Não é de hoje que a definição das aspirações coletivas acerca do progresso humano ocupa lugar de destaque na cena política mundial, tendo a Organização das Nações Unidas (ONU) como sua grande impulsionadora. A agenda de desenvolvimento contemporânea, especificamente, formalizada em 2015, apresenta-se como um arranjo de dimensão global, do ponto de vista dos atores envolvidos e da natureza transfronteiriça dos problemas que enfrenta, assim como, sob o prisma de seu conteúdo, encampa uma multiplicidade de temas- envolvendo todas as dimensões do mundo da vida -, articulados em torno da ideia de sustentabilidade.

Nessa perspectiva, o objetivo geral deste artigo consiste em investigar como a Agenda 2030 das Nações Unidas, projeto de desenvolvimento para o período pós-2015, afigura-se no marco da governança global para o desenvolvimento sustentável. Enquanto objetivos específicos, pretende-se apresentar, histórica e cronologicamente, aspectos da institucionalização do conceito de desenvolvimento sustentável no âmbito da ONU, além de compreender a abordagem pluridimensional do desenvolvimento sustentável anunciada na Agenda 2030.

Para tanto, e do ponto de vista metodológico, por se tratar de um estudo teórico, a pesquisa é de caráter qualitativo e utiliza o método dedutivo. Quanto aos procedimentos técnicos, trata-se de pesquisa bibliográfica, com consulta às literaturas brasileira e estrangeira, neste último caso com traduções livres dos autores. Ademais, o artigo encontra-se estruturado em duas partes.

Inicialmente, analisa-se, de forma breve, o conceito de governança e a possibilidade de sua expressão na ausência de um governo, com ênfase à governança exercida no nível global. Entendendo-se a cooperação entre diversos atores, em prol do enfrentamento dos desafios contemporâneos, como uma das facetas da governança, e considerando que o desenvolvimento sustentável é frequentemente apresentado como fórmula, quase mágica, para a resolução dos problemas globais, ensaia-se, também neste primeiro momento, uma aproximação entre as temáticas. Nesse sentido, traçam-se aspectos centrais da incorporação do tema "desenvolvimento sustentável" na agenda política da ONU ao longo das últimas quatro décadas, e estuda-se como as diferentes roupagens que o conceito foi assumindo, nesse período, foram sendo refletidas nas Conferências e documentos multilaterais da Organização.

A segunda parte do estudo debruça-se sobre a Agenda 2030, e seus respectivos Objetivos de Desenvolvimento Sustentável (ODS), enquanto o mais recente instrumento de governança global para o desenvolvimento apresentado pela ONU. Primeiramente, a partir da comparação com os Objetivos de Desenvolvimento do Milênio (ODM), antecessores dos ODS, demarca-se o porquê da singularidade do novo projeto. Ainda, ao passo em que se apresentam os aspectos centrais da Agenda, como a opção pela abordagem pluridimensional do desenvolvimento sustentável, abordam-se conceitos de governança implicados no plano de ação pós-2015, incursionando-se, por exemplo, pelas noções de governança por meio de metas e boa governança.

Não é demais lembrar que este estudo, partindo de um recorte transversal eaproximativo dos temas "governança" e "desenvolvimento sustentável", fornece um apanhado de primeiras impressões acerca da Agenda 2030, sem o compromisso, portanto, de proceder a uma análise mais profunda ou extensa das potencialidades e lacunas do projeto. 


\section{GOVERNANÇA GLOBAL E A INSTITUCIONALIZAÇÃO DO DESENVOLVIMENTO SUSTENTÁVEL NO ÂMBITO DA ONU}

O fim da Guerra Fria, nos anos 1990, simbolizou a passagem de um cenário internacional marcado pelo conflito e a rivalidade entre os Estados - e, especialmente, entre as superpotências -, predominante em boa parte do século XX, para um novo quadro no qual as transformações provocadas pela globalização fizeram emergir temas de debate público demandantes da cooperação global. Preocupações de ordem ambiental, social, econômica e política, decisivas para a vida na Terra e impossíveis de serem enfrentadas apenas com políticas nacionais, passaram a exigir a gestão compartilhada pelos Estados, sociedade civil, negócios, e, sobretudo, organizações com algum impacto em termos de governança global.

Desde o relatório de Brundtland, em 1987, que, como se verá, foi o responsável por popularizar o termo desenvolvimento sustentável, alertava-se sobre a existência de uma crise planetária, constituída por problemas interconectados: "[...] as várias crises globais não são crises separadas: uma crise ambiental, uma crise de desenvolvimento, uma crise de energia. Todas elas são apenas uma crise" (UN, 1987, p. 4). Reconhecendo essas conexões, o Clube de Roma cunhou o termo "global problématique", em referência a um conjunto interligado de grandes problemas sistêmicos - envolvendo, por exemplo, meio ambiente, demografia, desenvolvimento e novas tecnologias -, em constante modificação (REID, 2013, p. 10).

Não por acaso, a ideia de governança global logo começou a ser apresentada como mecanismo para o enfrentamento desses desafios transnacionais, recebendo o conceito destacada projeção na metade dos anos 1990, com o advento do relatório "Our Global Neighbourhood”, da Comissão de Governança Global da ONU. Na ocasião, governança foi definida como a totalidade das formas utilizadas por indivíduos e instituições, públicas e privadas, para gerenciarem seus assuntos comuns, "[...] um processo contínuo pelo qual interesses conflitantes ou diversos podem ser acomodados e ações cooperativas podem ser tomadas" (CGG, 1995, n.p). No nível global, informa o documento, embora a governança tenha se apresentado, historicamente, como relações entre governos, a partir do fenômeno globalizante passou a envolver, também, organizações não-governamentais, movimentos da sociedade civil, corporações transnacionais e o mercado de capitais global, atores que, com influência ampliada, estão engajados na promoção de objetivos de impacto global considerável.

Para Gonçalves (2005, n.p), governança é "o meio e o processo capaz de produzir resultados eficazes, sem necessariamente utilizar da coerção". Embora o conceito não indique a atuação isolada da sociedade civil, na busca por sua afirmação no cenário político, é inegável que o surgimento de atores diferentes do tradicional Estado-nação desempenha papel central para o desenvolvimento da ideia e da prática da governança.

Conforme Rosenau (2000, p. 13-15), o contínuo deslocamento da autoridade do Estado, seja no âmbito externo, em direção às entidades supranacionais, seja no domínio interno, em direção aos grupos subnacionais, tornou cada vez mais necessário aferir os contornos da governança existente na ausência de um governo. O governo, como esclarece o autor, pressupõe uma autoridade formal sustentando as atividades que asseguram a implementação de certos objetivos. No entanto, e para além dessa possibilidade, a governança caracteriza-se mesmo na ausência de responsabilidades legais ou poder de polícia. Isto é, a governança é fenômeno de maior amplitude que o governo, “[...] abrange as instituições governamentais, mas implica também mecanismos informais, de caráter não-governamental, que fazem com que as pessoas e as organizações dentro de sua área de atuação tenham uma conduta determinada" (ROSENAU, 2000, p. 15). 
Dentro dos três níveis que estruturam a ordem mundial, a governança situa-se no terceiro, denominado nível político ou agregado, no qual as instituições e os regimes voltados para a ordenação executam as políticas relativas aos dois primeiros níveis - o comportamental e o ideacional. Este estrato de atividade corresponde à dimensão mais organizada da ordem mundial, comportando instituições e regimes instituídos pelos diferentes atores do sistema, como a ONU, que, ao refletirem as próprias aspirações desses atores, dão forma aos entendimentos por meio dos quais a política global se desenvolve (ROSENAU, 200o, p. 28-29).

A noção de governança global encontra-se, portanto, fortemente vinculada a da existência de organizações internacionais, e, do ponto de vista de seu mérito, é possível inferir que remete à tentativa de solucionar os problemas coletivos gerados pelos desafios da contemporaneidade. A convergência de tais ideias subsidia a aproximação teórica que se pretende tecer neste estudo, afinal, o desenvolvimento sustentável vem sendo ventilado, pelo menos desde a década de 1980, como uma alternativa para o enfrentamento das crises globais, e a ONU, enquanto importante instituição de governança, esteve, e continua, na vanguarda das discussões que envolvem o tema.

A institucionalização do desenvolvimento sustentável, no âmbito desta organização, encontra suas raízesna Conferência das Nações Unidas sobreo MeioAmbientee Desenvolvimento Humano, realizada em Estocolmo, em 1972. Pela primeira vez a ONU introduzia a questão ambiental - um dos pilares de um desenvolvimento que se pretende sustentável - em sua agenda; daí a importância do evento. A Declaração resultante da Conferência consagrou o meio ambiente como direito fundamental, estabelecendo a proteção e a melhoria do meio físico como contrapartidas necessárias ao desfrute deste direito (TETREAULT, 2004, p. 47).

Não obstante, nos bastidores da Conferência, o clima entre os líderes dos países desenvolvidosedos países em desenvolvimento indicava um cenário poucofavorávelà persecução de objetivos ambientais. Predominava entre os governos dos países em desenvolvimento o discurso de que a preocupação ambiental consistia em um luxo dos países ricos: "[...] a pressão em favor dos limites ambientais era vista como um instrumento utilizado pelo Norte para bloquear o desenvolvimento econômico dos países emergentes" (VARELLA, 2003, p. 30). Tal circunstância conduziu diplomatas dos Estados do Sul a oporem-se à problemática ambiental, num primeiro momento, e defenderem para si o mesmo direito de desenvolvimento econômico que a maioria dos países do Norte já havia experimentado.

De todo modo, a Conferência de Estocolmo motivou a criação do Programa das Nações Unidas para o Meio Ambiente, concebido com o propósito de orientar projetos voltados à proteção ambiental no Sistema das Nações Unidas e promover a cooperação internacional sobre questões ligadas ao meio ambiente (TETREAULT, 2004, p. 47). Aliás, Maurice Strong, primeiro diretor executivo do programa, foi o responsável por cunhar, em 1973, o termo "ecodesenvolvimento", ensejando indicar uma política de desenvolvimento alternativa, que levasse em conta o impacto do crescimento econômico no meio ambiente físico (DRESNER, 2002, p. 31).

Seguindo essa linha, e na tentativa de aproximar as agendas "desenvolvimentistas" e "ambientalistas", a Assembleia Geral da ONU fundou, em 1983, da Comissão Mundial sobre Meio Ambiente e Desenvolvimento, com o propósito principal de "[...] conciliar a preocupação com a proteção ambiental no Norte com o desejo de desenvolvimento econômico no Sul" (DRESNER, 2002, p. 35). Passados quatro anos desde a sua criação, a Comissão apresentou o relatório "Nosso Futuro Comum", no qual definiu como sustentável o desenvolvimento “[...] capaz de atender às necessidades do presente sem comprometer a capacidade das futuras gerações para atender às suas necessidades" (UN, 1987, p. 16). 
De acordo com Bosselmann (2017, 28), a satisfação das necessidades humanas, mencionada no conceito, implicaria na busca conjunta de objetivos ambientais e de desenvolvimento. Afinal, "como um ambiente protegido pode atender às necessidades básicas dos pobres, se nenhum desenvolvimento ocorrer, e como o desenvolvimento pode ser benéfico, se ele vem ao preço da perda do meio ambiente?” (BOSSELMANN, 2017, p. 28).

A importância das questões suscitadas pelo relatório logo fez com que a temática do desenvolvimento sustentável fosse definitivamente incorporada ao repertório da ONU, e as conferências que tiveram lugar nos anos seguintes transformaram a Organização no "lar institucional" do termo cunhado por Gro Harlem Brundtland e sua Comissão.

O mais significativo desses eventos de cúpula aconteceu no Rio de Janeiro, em 1992. Contando com a participação de líderes de mais de cento e sessenta países, além de grandes grupos de interesses não governamentais e da iniciativa privada, a Conferência das Nações Unidas sobre o Meio Ambiente e o Desenvolvimento, também chamada Rio 92, apresentou relevância política muito superior à Conferência de Estocolmo, uma vez que, vinte anos antes, o desenvolvimento sustentável não figurava como um problema político central (DRESNER, 2002, p. 48).

Entre os legados da Rio $92^{3}$ no tocante à governança do desenvolvimento sustentável, destaca-se a construção da Agenda 21, plano de ação global sobre o desenvolvimento no século vindouro. Dividido em 40 capítulos, o documento apresentou propostas em quatro eixos: a) áreas social e econômica (combate à pobreza, mudança dos padrões de consumo, proteção da saúde humana, etc.); b) conservação e gestão dos recursos para o desenvolvimento (proteção da atmosfera, manejo da biotecnologia, proteção dos recursos hídricos, etc.); c) fortalecimento do papel de potenciais agentes da transição para uma trajetória sustentável (ação mundial pelas mulheres, encorajamento das populações indígenas, das autoridades locais, dos trabalhadores e sindicatos, etc.); e d) meios de implementação (financiamento, atuação de entidades governamentais e não-governamentais, etc.) (UNCED, 1992, n.p).

Para acompanhar a implementação da Agenda, a Assembleia Geral da ONU estabeleceu, em dezembro de 1992, a Comissão das Nações Unidas sobre o Desenvolvimento Sustentável (CSD), que veio a ocupar o lugar da Comissão Mundial sobre Meio Ambiente e Desenvolvimento. Conforme recomendado no capítulo 40 da Agenda 21, a CSD foi incumbida de desenvolver um conjunto de indicadores, para avaliar os progressos em direção à sustentabilidade, entendendose que o emprego dessa ferramenta auxiliaria a "orientar a tomada de decisão política para o desenvolvimento sustentável” (SPANGENBERG; PFAHL; DELLER, 2002, p. 106). Na asserção de Spangenberg, Pfahl e Deller (2002, p. 106), embora a Agenda 21 não tenha mencionado explicitamente a dimensão institucional do desenvolvimento sustentável, a atuação preocupada da CSD em relação às decisões políticas e à realização de atividades, por meio de organizações e redes de atores governamentais e não governamentais, consagrou de vez a existência de um quarto pilar da sustentabilidade.

A propósito, parte de Spangenberg et al. (1995, p. 3) uma contribuição de relevo ao paradigma do desenvolvimento sustentável, que muito influenciou, inclusive, a abordagem da ONU sobre o tema na primeira metade do século XXI. O prisma da sustentabilidade por ele formulado compreende quatro dimensões de igual importância: a ambiental, definida como a totalidade de processos bio-geológicos e os elementos neles envolvidos ("capital ambiental"); a social, consistindo nas qualidades intrapessoais dos seres humanos ("capital humano"); a econômica, incluindo todos os tipos de atividade que fornecem serviços a indivíduos e, assim,

3 A Conferência deu ensejo à adoção de dois acordos multilaterais voltados precipuamente para a questão ambiental, a ConvençãoQuadro sobre as Mudanças Climáticas e a Convenção sobre a Diversidade Biológica, além de seu final, a Declaração do Rio sobre o Meio Ambiente e da própria Agenda 21. Paralelamente aos instrumentos oficiais, as organizações não-governamentais negociaram quinze tratados alternativos, entre os quais, a Carta da Terra (BOSSELMANN, 2017, p. 32). 
aumentam o padrão de vida; e a institucional, resultado de processos interpessoais e sistemas de regras que governam a interação dos membros de uma sociedade (SPANGENBERG et al., 1995, p. 3; SPANGENBERG; PFAHL; DELLER, 2002, p. 105).

Esse conceito pluridimensional foi endossado pelos membros da ONU, em 2002, quando, reunidos em Johanesburgo, além de ratificarem seu compromisso com o desenvolvimento sustentável, promoveram um balanço dos dez anos da Agenda 21. O diagnóstico apontou uma série de dificuldades na efetivação da Agenda, especialmente no tocante à diminuição da pobreza, cuja situação teria se agravado desde 1992, devido à redução dos níveis de ajuda financeira internacional, ao crescimento das dívidas externas e ao insucesso no aperfeiçoamento de medidas como a transferência de tecnologia e coordenação institucional (SEQUINEL, 2002, p. 12). No entanto, pouco se avançou com a realização da cúpula, muito em razão da conjuntura geopolítica desfavorável do momento.

Se na Rio 92, após a queda do Muro de Berlim e ao fim da Guerra Fria, imperava a lógica da cooperação, em vez da do conflito, a Rio +1o transcorreu em um cenário oposto, no qual a gritante desigualdade entre os países impediu o consenso em vários temas. A proposta brasileira de substituir as matrizes energéticas poluidoras por fontes renováveis de energia em $10 \%$ até 2010, por exemplo, foi rejeitada pelo bloco Juscanz (Japão, Estados Unidos, Canadá, Austrália, e Nova Zelândia), que, amplamente apoiado por países árabes - não por acaso, importantes produtores de petróleo -, defendeu de forma intransigente seus interesses (SEQUINEL, 2002, p. 13). Na síntese de Sequinel (2002, p. 14), este foi o espírito de Johanesburgo: "[d]iversidade de opiniões e posturas, muitas vezes conflitantes".

A terceira grande conferência da ONU sobre desenvolvimento sustentável, a Rio +20, realizada em 2012, escancarou um paradoxo tão real quanto indesejável: a existência de uma “[...] enorme lacuna entre onde a ONU gostaria que o mundo estivesse e onde ele realmente se encontrava" (CARADONNA, 2016, p. 156). Nessa senda, a conferência foi marcada por lamentações sobre os esforços fracassados para a transição ao tipo de ordem global sustentável previsto em 1992, mas, também, pela renovação do compromisso político com a causa da sustentabilidade (CARADONNA, 2016, p. 151-152).

Por conseguinte, no relatório final da Rio +20 , denominado "O futuro que queremos", reconheceu-se a necessidade de uma melhor integração dos aspectos econômicos, sociais e ambientais do desenvolvimento sustentável em todos os níveis (ONU, 2012, p. 3) e a possível utilidade da definição de objetivos para a busca de ações focadas e coerentes para o desenvolvimento sustentável (ONU, 2012, p. 48). Nesse propósito, o documento foi além, e forneceu diretrizes para a construção dos Objetivos de Desenvolvimento Sustentável (ODS): "[d]estacamos que os objetivos de desenvolvimento sustentável (ODS) devem ser orientados para a ação, concisos e fáceis de entender, em número limitado, ambiciosos, de natureza global, e universalmente aplicáveis a todos os países, tendo em conta as diferentes realidades" (ONU, 2012, p. 49).

Formalizava-se, então, a intenção de construir uma nova agenda de desenvolvimento, alicerçada na ideia de governança por meio de objetivos não vinculantes, que pudesse dar novo ímpeto à mobilização social em torno de um desafio que já somava mais de quarenta anos de debate público. Esse projeto, denominado "Transformando nosso mundo: a Agenda 2030 das Nações Unidas", representa a completa incorporação do conceito pluridimensional de desenvolvimento nos instrumentos da ONU, e pretende alcançar sucesso por meio de um arranjo de governança multiatores e multinível, como se verá adiante. 


\section{ALICERÇANDO O DESENVOLVIMENTO EM OBJETIVOS: A AGENDA 2030 DAS NAÇÕES UNIDAS}

Em setembro de 2015, a Assembleia Geral das Nações Unidas (ONU) adotou 17 objetivos e 169 metas como parte integrante da agenda política global sobre o desenvolvimento no período pós-2015. Os Objetivos de Desenvolvimento Sustentável (ODS) foram construídos e ampliados no escopo dos Objetivos de Desenvolvimento do Milênio (ODM) - experiência primeira da inserção de metas no centro da governança global -, adotados em 2000.

Os ODM representaram um efetivo método de mobilização em torno de importantes questões em todo o mundo, ajudando a despertar a consciência sobre a magnitude dos problemas globais. A síntese da prioridade pública, nos primeiros anos do milênio, envolvia a preocupação com a pobreza, fome, doenças, falta de acesso à educação, desigualdade de gênero e degradação do meio ambiente, prioridades essas que foram reunidas em um conjunto de oito objetivos. O cumprimento do referido itinerário, no entanto, deu-se heterogeneamente, com progresso variável a depender dos objetivos, dos países e das regiões de incidência (SACHS, 2012, p. 2206).

Não obstante, os ODS não representam a mera continuidade dos ODM: enquanto esses últimos tinham como espinha dorsal o desenvolvimento social e econômico, os novos objetivos maquinam de forma integrada e indivisível as quatro dimensões conformadoras do desenvolvimento sustentável, o que diferencia substancialmente os dois projetos. Por outro lado, ao passo em que os ODM destinavam-se, principalmente, aos países pobres, cabendo aos ricos acrescentarem sua solidariedade e assistência por meio de financiamento e tecnologia, os ODS possuem abordagem ampliada, envolvendo todo o planeta (SACHS, 2012, p. 2208), e, como a própria Agenda 2030 assevera, pretendendo "não deixar ninguém para trás" (ONU, 2015, p. 3 e 16).

Para Biermann, Kanie e Kim (2017, p. 27), outro aspecto que faz dos ODS uma experiência inovadora consiste na ampla participação pública em seu processo de concepção, o qual contou com contribuições de pelo menos 70 países e de numerosos representantes da sociedade civil - trabalhando no "Grupo Aberto para a elaboração dos ODS" -, diferentemente do que havia sucedido com os ODM, cuja elaboração deu-se essencialmente por experts de um Secretariado da ONU. Ainda, na análise dos autores, ao contrário dos ODM, os ODS usam a nomenclatura "países industrializados" e "países em desenvolvimento", abordagem que, conceitualmente, “[...] identifica nenhum país como 'desenvolvido' em termos de sustentabilidade, e transforma todos os países na América do Norte, Europa, Ásia Oriental e Oceania em 'países em desenvolvimento' que têm que apresentar planos para transformar suas sociedades” (BIERMANN; KANIE; KIM, 2017, p. 27).

Traçadas essas diferenciações que permitem antever o porquê da singularidade da Agenda 2030, cabe apresentar os principais pontos do projeto, que se reveste de autêntico programa civilizatório. De antemão, destaca-se que o documento é composto por quatro partes: uma Declaração, que reflete a visão, os princípios e os compromissos da ONU; um quadro de resultados, indicativo dos 17 ODS e suas 169 metas; uma seção sobre meios de implementação e de parcerias globais; e um roteiro para acompanhamento e revisão.

Em nível preambular, encontram-se definidas as áreas "de importância crucial" no processo de efetivação da Agenda, quais sejam: as Pessoas, o Planeta, a Prosperidade, a Paz e a Parceria. O fim da pobreza, em todas as suas formas e dimensões, por sua vez, recebe o status de maior desafio global e pressuposto para o desenvolvimento sustentável. O preâmbulo também informa que os objetivos e metas condutores da ação nos 15 anos subsequentes "[...] 
são integrados e indivisíveis, e equilibram as três dimensões do desenvolvimento sustentável: a econômica, a social e a ambiental" (ONU, 2015, p. 1).

$\mathrm{Na}$ intenção de esclarecer brevemente o significado de cada uma dessas dimensões, e com lastro nas contribuições de Harris et al. (2001, p. 29), vislumbra-se como economicamente sustentável o sistema capaz de produzir bens e serviços continuamente, manter níveis administráveis de dívida interna e externa, e evitar desequilíbrios setoriais extremos, capazes de prejudicar a produção agrícola ou industrial.

A sustentabilidade social, por seu lado, é garantida quando há justiça na distribuição de renda e de oportunidades, provisão adequada de serviços sociais, incluindo saúde e educação, além de participação política ativa (HARRIS et al., 2001, p. 29). A par de uma abordagem mais coletivizada do viés social, tem forte apelo, nesse domínio, a questão do desenvolvimento humano, no guião da ampliação das capacidades individuais, e dentro da lógica defendida, principalmente, por Sen (200o, p. 32).

Adimensãoambientaldodesenvolvimentosustentável, porfim, apontaparaa necessidade de uma base de recursos naturais estável, na qual não haja espaço para a superexploração de recursos renováveis ou esgotamento de recursos não renováveis. Nas palavras de Harris et al. (2001, p. 29), "[i]sso inclui a manutenção da biodiversidade, da estabilidade atmosférica e de outras funções do ecossistema”.

Diferente do que se poderia imaginar, a ausência de menção expressa à dimensão político-institucional não significa que ela tenha sido esquecida, visto que, ao longo da Agenda, são inúmeras as referências à atuação dos atores para a efetivação das propostas ali entabuladas. Para Sachs (2017, p. 502-503), o aspecto político-institucional do desenvolvimento sustentável confunde-se com a ideia de boa governança, a qual exige a comunhão de certos princípios pelos setores público e privado.

O primeiro desses princípios é a responsabilidade. Todos os atores comprometidos com a Agenda 2030 são responsáveis por efetivá-la, o que implica no delineamento de medidas hábeis ao alcance dos ODS e na exposição dos resultados obtidos nesse intento. Da noção de prestação de contas decorre um segundo princípio, a transparência: "[...] como cidadãos, como participantes do mercado e, sobretudo, como seres humanos com intenção de alcançar o desenvolvimento sustentável, só poderemos responsabilizar o governo e os negócios por suas ações se conhecermos essas ações e comportamentos" (SACHS, 2017, p. 503).

A participação, capacidade de as partes interessadas colaborarem na tomada de decisão, aparece como o terceiro princípio da boa governança. "Participar", na explicação de Sachs (2017, p. 504), vai além do exercício do voto durante o pleito eleitoral, compreende, por exemplo, a atuação nos conselhos - consultivos e deliberativos, existentes em todos os níveis (federal, estadual, regional e municipal) e acerca de várias áreas - e a voz ativa nas audiências públicas.

No mesmo sentido, ao defender que a governança para o desenvolvimento sustentável pressupõe um processo de direção social, Meadowcroft (2000, p. 111) destaca o papel da discussão coletiva para a definição das linhas de desenvolvimento a serem adotadas. A governança para o desenvolvimento sustentável, afirma o autor, 'é 'interativa', não apenas no sentido instrumental de que as contribuições sociais podem facilitar o progresso em direção aos objetivos delineados, mas também no sentido mais profundo de que os objetivos em si devem ser definidos coletivamente" (MEADOWCROFT, 200o, p. 111). Portanto, parece indispensável à existência de um ambiente democrático como plano de fundo para a busca do desenvolvimento sustentável.

Dando continuidade à análise da Agenda 2030, cabe investigar o núcleo do documento, isto é, os Objetivos de Desenvolvimento Sustentável. Eles são assim anunciados: "Acabar com a pobreza em todas as suas formas, em todos os lugares" (Objetivo 1); "Acabar com a fome, 
alcançar a segurança alimentar e melhoria da nutrição e promover a agricultura sustentável" (Objetivo 2); "Assegurar uma vida saudável e promover o bem-estar para todos, em todas as idades" (Objetivo 3); "Assegurar a educação inclusiva e equitativa e de qualidade, e promover oportunidades de aprendizagem ao longo da vida para todos" (Objetivo 4); "Alcançar a igualdade de gênero e empoderar todas as mulheres e meninas" (Objetivo 5); "Assegurar a disponibilidade e gestão sustentável da água e saneamento para todos" (Objetivo 6); "Assegurar o acesso confiável, sustentável, moderno e a preço acessível à energia para todos" (Objetivo 7); "Promover o crescimento econômico sustentado, inclusivo e sustentável, emprego pleno e produtivo e trabalho decente para todos" (Objetivo 8); "Construir infraestruturas resilientes, promover a industrialização inclusiva e sustentável e fomentar a inovação" (Objetivo 9); e "Reduzir a desigualdade dentro dos países e entre eles" (Objetivo 10).

Ainda: "Tornar as cidades e os assentamentos humanos inclusivos, seguros, resilientes e sustentáveis" (Objetivo 11); "Assegurar padrões de produção e de consumo sustentáveis" (Objetivo 12); "Tomar medidas urgentes para combater a mudança do clima e seus impactos" (Objetivo 13); "Conservação e uso sustentável dos oceanos, dos mares e dos recursos marinhos para o desenvolvimento sustentável" (Objetivo 14); "Proteger, recuperar e promover o uso sustentável dos ecossistemas terrestres, gerir de forma sustentável as florestas, combater a desertificação, deter e reverter a degradação da terra e deter a perda de biodiversidade" (Objetivo 15); "Promover sociedades pacíficas e inclusivas para o desenvolvimento sustentável, proporcionar o acesso à justiça para todos e construir instituições eficazes, responsáveis e inclusivas em todos os níveis" (Objetivo 16); e "Fortalecer os meios de implementação e revitalizar a parceria global para o desenvolvimento sustentável" (Objetivo 17) (ONU, 2015, p. 15).

De forma geral, e como se percebe, tais objetivos encampam uma abordagem de governança global em que a definição de metas constitui estratégia-chave. Para Sachs (2017, p. 490), basear a governança em metas é vantajoso, entre outros motivos, por que: a) possibilita que pessoas, organizações e os governos caminhem em direção comum, em um mundo marcado pelo excesso de informação; b) promove a "pressão dos pares", uma vez que o avanço (ou a falta dele) na efetivação dos objetivos é relatado e serve de termo de comparação entre os Estados; c) mobiliza comunidades epistêmicas, redes de pesquisa e práticas, em torno de desafios específicos.

Não é demais lembrar que o documento que estabeleceu os ODS - uma resolução da Assembleia Geral da ONU - situa-se fora do sistema legal internacional, não contando com força jurídica vinculante. Portanto, apesar do evidente potencial do conjunto de objetivos, o seu sucesso dependerá de uma série de fatores institucionais, como, por exemplo, o comprometimento dos Estados na tradução das ambições globais aos contextos nacionais e na integração das metas de desenvolvimento sustentável às políticas setoriais (BIERMANN; KANIE; KIM, 2017, p. 26).

Mais do que o envolvimento do tradicional ator estatal, a Agenda 2030 sublinha a necessidade de uma parceria global revitalizada, que trabalhe em um "[...] espírito de solidariedade global, em especial a solidariedade com os mais pobres e com as pessoas em situação vulnerável" (ONU, 2015, p. 13, grifos nossos), e eluda também o setor privado - "desde as pequenas empresas e cooperativas até as multinacionais" -, a sociedade civil e outros atores. Essa prescrição decorre, em última análise, da própria natureza do desenvolvimento sustentável, que, na asserção de Silveira e Sanches, enquadra-se nos chamados direitos de solidariedade, por expressar "necessidades e anseios comuns a toda humanidade, cuja concretização depende da ação de todos" (2015, p. 145). 
Nesse ínterim, e especificamente no tocante à atuação das empresas, destacam os referidos autores, que no cumprimento de sua função social, esses agentes econômicos devem prezar pela realização de objetivos relacionados ao interesse coletivo. Esse compromisso, porém, não se limita apenas ao cumprimento das obrigações legais e ao respeito aos direitos sociais trabalhistas e tributários, compreendendo a preservação ambiental, a ética nas relações com fornencedores e consumidores, bem como a atenção com os reflexos de sua atuação na comunidade em que se encontra inserida (SILVEIRA; SANCHES, 2015, p. 151). Há, pois, além da função social, uma função solidária, na conclusão de Silveira e Sanches (2015, p. 151).

Além disso, e em arremate às disposições acerca da governança no bojo da Agenda 2030, dentro do ODS 17, que refere particularmente à implementação do projeto, fala-se em "parcerias multissetoriais", que mobilizem e compartilhem conhecimento, tecnologia e recursos financeiros, suscitando questões cruciais para a promoção do desenvolvimento sustentável, como a transferência tecnológica, o financiamento internacional e alívio da dívida externa (SACHS, 2017, p. 490-491).

O conciso exame da Agenda 2030 aqui empreendido permite afirmar que, pelo menos no plano institucional, o desenvolvimento sustentável apresenta-se como a versão mais contemporânea da própria noção de desenvolvimento. Afinal, a Agenda 2030 foi construída sobre o escorço e em substituição aos Objetivos de Desenvolvimento do Milênio, e, ao acrescentar o adjetivo "sustentável" aos seus objetivos, a ONU inaugura um pretenso novo projeto civilizatório, mais simpático à tarefa de equacionar o desenvolvimento econômico com a proteção ambiental, valores que, historicamente, mostraram-se antagônicos. Considerada em si mesma, a Agenda constitui instrumento de governança global, à medida que serve de guia para os Estados, as organizações intergovernamentais e não-governamentais, a sociedade civil e o setor econômico, rumo a construção de um mundo assentado em práticas sociais, produtivas e negociais mais prudentes.

\section{CONSIDERAÇÕES FINAIS}

O presente estudo versou sobre a governança global e o desenvolvimento sustentável, temáticas que, na sua complexidade, encontram-se articuladas na Agenda 2030 das Nações Unidas. Na breve exposição empreendida, alguns aspectos ficaram bastante evidentes.

Como demonstrado, o descolamento da noção de governança da de governo albergou a possibilidade de que organizações desprovidas de meios coercitivos exercessem influência e coordenassem ações de outros atores em direção a determinados fins. Nesse quadrante, o desenvolvimento sustentável tem tido a ONU como sua impulsionadora pelo menos desde a década de 1970, passando a integrar a agenda política da Organização de modo incipiente, com os primeiros esboços conceituais, e, posteriormente, sendo alavancado como uma saída para as crises globais.

O afamado conceito de desenvolvimento sustentável apresentado por Brundtland, em 1987, e largamente adotado em uma sucessão de Conferências sobre o tema, por implicar um desejável compromisso ético das gerações presentes para com as futuras, ficou conhecido como "intergeracional". No entanto, esse conceito foi cedendo lugar para uma abordagem holística, de equilíbrio de dimensões.

Nessa esteira, o desenvolvimento sustentável passou a caracterizar-se como um meta-objetivo político aglutinador de medidas ambientais, econômicas, sociais e políticoinstitucionais, capazes de promoverem o bem-estar das pessoas e do planeta. Ainda que a noção pluridimensional do desenvolvimento estivesse "às voltas" com os instrumentos da ONU 
desde a Agenda 21, de 1992, o documento a incorporá-la de forma mais clara foi a Agenda 2030, quando, em seu preâmbulo, assinalou que os 17 objetivos ali anunciados estariam a equilibrar as três dimensões do desenvolvimento sustentável.

A Agenda 2030 da ONU constitui, pois, um instrumento de governança por meio de metas que, nos moldes da Declaração do Milênio, sua antecessora, mas, de modo singular, lança os fundamentos de um projeto de desenvolvimento com potencial para ser compartilhado por todos os países do mundo. Apresenta, em verdade, diretrizes gerais, sem, contudo, deixar de ponderar sobre a necessidade de cada Estado adequá-las às suas realidades e prioridades.

Como se assinalou a realização desse ambicioso plano depende de uma parceria multinível, abrangendo diferentes atores públicos e privados, numa combinação harmonizada de governança com e sem governo. Por outro lado, em sua substância, as ações precisam ser pautadas por princípios de boa governança, como a transparência. Apenas assim, ao que parece, haverá justiça na repartição das oportunidades e das responsabilidades implicadas pelo desenvolvimento.

\section{REFERÊNCIAS BIBLIOGRÁFICAS}

BIERMANN, Frank; KANIE, Norichika; KIM, Rakhyun E. Global governance by goal-setting: the novel approach of the UN Sustainable Development Goals. Current Opinion in Environmental Sustainability, [S.1], v. 26, p. 26-31, 2017. Disponível em: $<$ https://www.sciencedirect.com/science/ article/pii/S1877343517300209>. Acesso em: 18 fev. 2019.

BOSSELMANN, Klaus. The principle of sustainability: transforming law and governance. 2. ed. New York: Routledge, 2017.

CARADONNA, Jeremy L. Sustainability: a history. New York: Oxford University Press, 2016.

COMMISSION ON GLOBAL GOVERNANCE. Our global neighbourhood: The report of the commission on global governance. 1995. Disponível em: $<$ http://www.gdrc.org/u-gov/globalneighbourhood/>. Acesso em: 10 fev. 2019.

DRESNER, Simon. The principles of sustainability. New York: Routledge, 2002.

GONÇALVES, Alcindo. O conceito de governança. XIV Encontro do Conpedi, v. 16, 2005. Disponível em: $<$ https://social.stoa.usp.br/articles/0016/1432/GovernanA_a100913.pdf $>$. Acesso em: 27 fev. 2019.

HARRIS, Jonathan M.; WISE, Timothy A.; Gallagher, Kevin P.; GOODWIN, Neva R. A Survey of Sustainable Development: Social and Economic Dimensions. Washington, Covelo and London: Island Press, 2001.

MEADOWCROFT, James. Who is in charge here? Governance for sustainable development in a complex world. Journal of Environmental Policy \& Planning, [S.l], v. 9, n. 3-4, p. 299314, 2007. Disponível em:<https://www.researchgate.net/publication/248926024_Who_is_ in_Charge_here_Governance_for_Sustainable_Development_in_a_Complex_World>. Acesso em: 04 fev. 2019. 
ORGANIZAÇÃO DAS NAÇÕES UNIDAS. O Futuro Que Queremos: Declaração Final da Conferência das Nações Unidas sobre Desenvolvimento Sustentável (Rio + 20). 2012. Disponível em:<http://www2.mma.gov.br/port/conama/processos/61AA3835/O-Futuro-que-queremos1. pdf $>$. Acesso em: 20 fev. 2019.

. Transformando Nosso Mundo: a Agenda 2030 para o Desenvolvimento Sustentável. 2015. Disponível em:<http://www.br.undp.org/content/dam/brazil/docs/agenda203o/undp-brAgenda2030-completo-pt-br-2016.pdf>. Acesso em: 20 fev. 2019.

REID, David. Sustainable Development: an introductory guide. New York: Routledge, 2013.

ROSENAU, James N. Governança, ordem e transformação na politica mundial. In: ROSENAU, James N.; CZEMPIEL, Ernst-Otto (Orgs.). Governança sem governo: ordem e transformação na politica mundial. Trad. Sergio Bath. Brasilia: UNB, 200o. p. 11-46.

SACHS, Jeffrey D. From Millennium Development Goals to Sustainable Development Goals. The Lancet, [S.1], v. 379, n. 9832, p. 2206-2211, 2012. Disponível em: <http://www.thelancet. com/journals/lancet/article/PIISo140-6736(12)6o685-o/abstract>. Acesso em: 25 fev. 2019.

The Age of Sustainable Development. New York: Columbia University Press, 2017.

SEN, Amartya. Desenvolvimento como liberdade. Tradução Laura Teixeira Motta. São

Paulo: Companhia das Letras, 2000.

SEQUINEL, Maria Carmen Mattana. Cúpula mundial sobre desenvolvimento sustentávelJoanesburgo: entre o sonho e o possível. Análise conjuntural, v. 24, n. 11-12, p. 12-15, 2002.

SILVEIRA, Vladimir Oliveira da.; SANCHES, Samyra Haydêe Dal Farra Naspolini. Direitos humanos, empresa e desenvolvimento sustentável. Revista Direito e Desenvolvimento, João Pessoa, v. 6, n. 9, 2015, p. 145-156. Disponível em:<https://periodicos.unipe.br/index.php/ direitoedesenvolvimento/article/view/293/275>. Acesso em: 28 mar. 2019.

SPANGENBERG, Joachim H.; PFAHL, Stefanie; DELLER, Kerstin. Towards indicators for institutional sustainability: lessons from an analysis of Agenda 21. Ecological indicators, v. 2, n. 1-2, p. 61-77, 2002.

SPANGENBERG, Joachim H. (Ed.). Towards sustainable Europe: a study from the Wuppertal Institute for Friends of the Earth Europe. Luton/Bruxelas: FoE Publications, 1995.

TETREAULT, Darcy. Una taxonomía de modelos de desarrollo sustentable. Espiral, Bucaramanga, v. 10, n. 29, p. 45-77, 2004. Disponível em:<http://www.redalyc.org/ html/138/13802902/>. Acesso em: 5 fev. 2019.

VARELLA, Marcelo Dias. Direito internacional econômico ambiental. Belo Horizonte: Del Rey, 2003. 
UNITED NATIONS CONFERENCE ON ENVIRONMENT \& DEVELOPMENT. Agenda 21. Rio de Janeiro, 1992. Disponível em:<https://sustainabledevelopment.un.or =g/content/ documents/Agenda21.pdf. Acesso em: 17 fev. 2019.

UNITED NATIONS. World Commission on environment and development. Our Common Future: Report of the World Commission on Environment and Development. 1987. Disponível em: <http://www.undocuments.net/our-common-future.pdf>. Acesso em: 20 fev. 2019. 